\title{
Pra Desain Pabrik Produksi Gasoline Pada Kilang Minyak Skala Kecil
}

\author{
Bilal Chabibulloh, Wisnu Kusuma Atmaja, Juwari dan Renanto \\ Departemen Teknik Kimia, Fakultas Teknologi Industri, Institut Teknologi Sepuluh Nopember (ITS) \\ e-mail: joecheits@yahoo.com
}

\begin{abstract}
Abstrak-Ketergantungan masyarakat terhadap bahan bakar minyak, membuat bahan bakar minyak menjadi komoditas utama dan krusial di sektor energi,. Hal inilah yang menyebabkan Indonesia masih melakukan impor minyak bumi demi memenuhi kebutuhan BBM masyarakat. Saat ini, negara melalui PT. Pertamina (persero) menyediakan sekitar Rp1,15 triliun setiap hari untuk impor minyak mentah dan BBM. Dintaranya untuk impor BBM. Permasalahan lain mengenai BBM yang sering terjadi adalah masalah distribusi BBM ke seluruh pelosok negeri. Data menyebutkan bahwa distribusi penggunaan minyak bumi di Indonesia cenderung terpusat di Pulau Jawa. Di luar Pulau Jawa, bahan bakar minyak sangat sulit didapat. Faktanya, Indonesia memiliki cadangan minyak bumi yang tersebar hampir di setiap pulau. Namun, hal ini tidak didukung dengan jumlah kilang minyak bumi yang memadai. Salah satu solusinya adalah dengan membangun kilang-kilang baru. Namun, membangun kilang dengan skala besar dengan produksi minimum 300,000 bpd akan membutuhkan biaya yang besar dan waktu yang lama. Oleh karena itu pemerintah menargetkan pembangunan kilangkilang skala kecil untuk memenuhi kebutuhan BBM dalam negeri. Karena produksi minyak di Indonesia dalam skala kecil maka akan lebih efisien dan ekonomis bila membangun kilang mini $(<20,000$ bpd) di setiap daerah sumber crude oil. Berdasarkan analisis ekonomi, laju pengembalian modal (IRR) pabrik ini sebesar $43 \%$ pada tingkat suku bunga per-tahun $10,25 \%$ dan laju inflasi sebesar $3,35 \%$ per-tahun. Sedangkan untuk waktu pengembalian modal (POT) adalah 4,235 tahun dan titik impas (BEP) sebesar 54,18\% melalui pembuatan grafik linear BEP. Umur dari pabrik selama 10 tahun dan masa konstruksi selama 2 tahun. Untuk mengolah 10000 barrel crude oil per-hari menjadi beberapa produk diperlukan biaya total produksi (TPC) sebesar Rp 3.713.409.763.696,68 dengan biaya investasi total $R p$ 292.774.958.752,83 dan total hasil penjualan sebesar Rp 3.903.215.502.396,54 . Dengan memperhitungkan aspek penilaian analisa ekonomi dan teknisnya, maka Pabrik Produksi Gasoline pada Kilang Minyak Skala Kecil ini layak untuk didirikan.
\end{abstract}

Kata Kunci-Kilang, crude oil, gasoline blending.

\section{PENDAHULUAN}

$\mathrm{U}$ SAHA eksplorasi minyak bumi pertama kali di Indonesia dilakukan di kaki gunung Ciremai di Cirebon pada tahun 1871, namun tidak berhasil. Dengan dilatarbelakangi peranan penting minyak dan gas bumi, dilakukanlah usaha - usaha eksplorasi berikutnya pada tanggal 15 Juni 1885 di Telaga Tunggal daerah Pangkalan Brandan oleh Aelko Jan Zooen Zijkler dengan pengeboran di kedalaman 120 meter. Sumur tersebut merupakan sumur minyak pertama yang dilakukan Hindia Belanda yang berstandar internasional.

Kegiatan eksplorasi ini selanjutnya dilakukan pula kegiatan pengolahan minyak dan gas bumi. Pengolahan ini merupakan kegiatan utama dalam kegiatan usaha industri hilir minyak dan gas bumi. Pengolahan bertujuan untuk memurnikan minyak mentah (crude oil) menjadi produk- produk Bahan Bakar Minyak (BBM) dan Non Bahan Bakar Minyak (Non BBM) bernilai tinggi yang sangat dibutuhkan masyarakat. Pengolahan minyak bumi dilakukan di kilang-kilang baik yang di operasikan oleh Pertamina selaku Badan Usaha Milik Negara, serta pihak swasta yang tersebar diseluruh wilayah Indonesia yang bertujuan untuk memenuhi pasokan BBM Nasional.

Kilang Wonokromo di Jawa Timur adalah kilang minyak yang pertama kali beroperasi di Indonesia yaitu di tahun 1890 yang hampir berbarengan dengan Kilang Pangkalan Brandan di Sumatera Utara yang beroperasi sejak tahun 1891. Sejak saat itu, beberapa kilang dibangun pada masa pra-kemerdekaan [1].

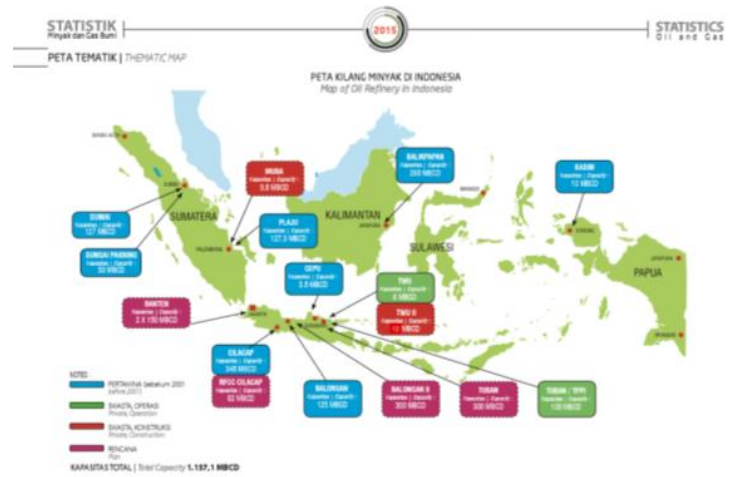

Gambar 1. Peta Persebaran Kilang Miny ak di Indonesia

Berdasarkan data yang ada, terlihat bahwa tingkat konsumsi BBM dan LPG nasional telah melebihi produksi minyak mentah dalam negeri sejak tahun 2001. Sehingga persoalan ini menyebabkan pemerintah harus mengimpor minyak mentah dan BBM untuk memenuhi konsumsi nasional. [1]. 


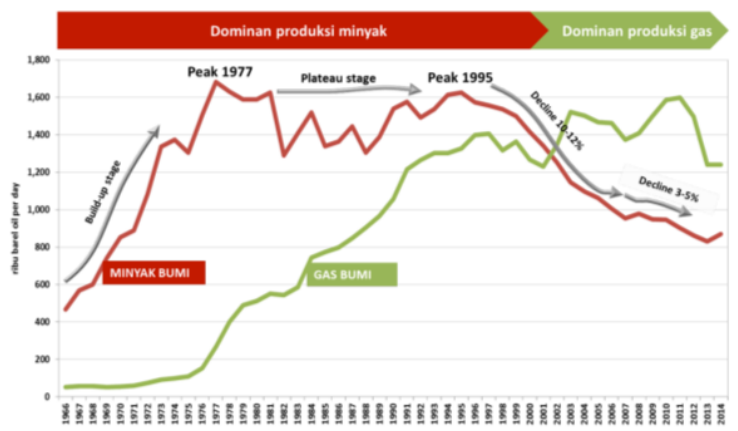

Gambar 1 . Grafik Produksi Minyak Nasional dan Konsumsi BBM Serta LPG

Hal tersebut cukup disayangkan mengingat Indonesia masih memiliki cadangan minyak yang tersebar hampir di setiap pulau yakni, Sumatera, Jawa, Kalimantan, Sulawesi, Maluku, Papua hingga pulau kecil lainnya. Seharusnya hal ini dapat dimanfaatkan oleh pemerintah. Selain itu, produksi minyak Indonesia juga masih dapat ditingkatkan. Salah satunya dengan membangun kilang-kilang baru untuk memenuhi dan meningkatkan kebutuhan produksi minyak di Indonesia.

Selain permasalahan impor minyak, masalah lain mengenai BBM yang acapkali terjadi adalah mengenai distribusi BBM yang tidak merata ke seluruh pelosok negeri. Negara Indonesia adalah negara kepulauan, dimana untuk menjangkau tiap-tiap pulaunya tidak cukup hanya melalui jalur darat, bahkan harus ditempuh melalui jalur laut dan jalur udara. Seharusnya seluruh daerah di Indonesia memiliki hak yang sama atas ketersediaan BBM yang cukup di daerah masing-masing. Namun pada kenyataannya hal tersebut belum terjadi dikarenakan tidak meratanya pembangunan infrastruktur termasuk pembangunan kilang.

Menurut Peraturan Menteri Energi dan Sumber Daya Mineral Republik Indonesia Nomor 22 Tahun 2016 tentang pelaksanaan pembangunan kilang minyak skala kecil di dalam negeri, definisi kilang minyak skala kecil adalah kilang minyak bumi atau kondensat beserta fasilitas pendukungnya yang memiliki kapasitas produksi maksimal sebesar 20.000 barel per hari. Yang disebut kondensat adalah cairan hasil dari kondensasi dari fase gas bumi pada tekanan dan temperatur atmosfer berupa fraksi pentana ke atas. Ada lima tujuan pembangunan kilang minyak skala kecil ini, yaitu:

1. Mewujudkan ketahanan energi nasional.

2. Menjamin ketersediaan bahan bakar minyak.

3. Efisiensi kegiatan usaha hulu dan hilir minyak dan gas bumi.

4. Mengurangi ketergantungan impor bahan bakar minyak.

5. Peningkatan perekonomian nasional dan daerah dengan cara pengoptimalan pemanfaatan minyak mentah dan kondensat hasil produksi dalam negeri.

Pembangunan kilang minyak skala kecil lebih memiliki banyak keuntungan dibanding dengan membangun kilang minyak skala besar seperti waktu perancangan dan pembangunan yang lebih singkat, lebih mudah untuk meningkatkan quality control, konsumsi energi yang lebih sedikit, penggunaan lahan yang lebih sedikit, lebih mudah untuk menjaga keamanan kerja, lebih mudah mengamankan kilang itu sendiri, dan masih banyak yang lain. Selain itu Indonesia lebih banyak menghasilkan minyak dari sumursumur yang banyak tersebar di penjuru nusantara, maka akan lebih efisien dan ekonomis apabila membangun kilang minyak skala kecil di lokasi dekat sumber minyak dibanding apabila membangun satu kilang besar dan minyak-minyak yang sumbernya jauh tadi harus dikirim ke kilang besar tersebut.

Berdasarkan fakta-fakta yang ada, untuk mewujudkan ketahanan energi nasional dengan cara menjamin ketersediaan bahan bakar minyak dan memaksimalkan produksi minyak dalam negeri, maka opsi yang dirasa tepat adalah dengan cara membangun kilang minyak skala kecil di daerah penghasil minyak.

\section{URAIAN PROSES}

\section{A. Tipe-Tipe Proses}

Minyak mentah yang diproduksi dari lapangan relatif memiliki harga jual yang rendah dikarenakan sangat jarang bisa digunakan secara langsung. Oleh karena itu perlu dilakukan adanya penyulingan minyak mentah menjadi produk-produk yang diinginkan. Kilang minyak memainkan peran penting dalam proses tersebut. Adapun secara umum, konfigurasi dari kilang minyak akan dikelompokkan sesuai dengan kemampuan pemrosesannya dan terbagi dalam empat konfiguras i, yakni:

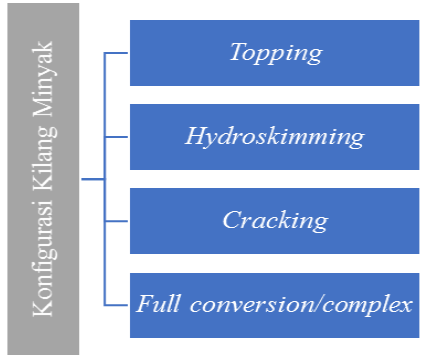

Gambar 2. Jenis Konfigurasi Umum Kilang Minyak

\section{Topping Refinery}

Topping Refinery merupakan jenis konfigurasi yang paling sederhana. Proses penyulingan pada jenis konfigurasi ini utamanya terdiri dari unit atmospheric crude unit yang menghasilkan produk berupa light ends $\left(\mathrm{C}_{1}-\mathrm{C}_{4}\right)$, naptha, kerosene, dan diesel. Atmospheric residue yang dihasilkan umumnya dijual sebagai fuel oil atau sebagai produk antara [2].

Produk yang dihasilkan oleh kilang dengan konfigurasi ini tidak memerlukan perlakuan tambahan seperti pemrosesan secara kimia untuk merubah range dari titik didih minyak mentah (cracking, coking) ataupun untuk meningkatkan karakteristik produk (seperti dengan reforming atau hydrotreating).

\section{Hydroskimming}

Hydroskimming merupakan konfigurasi kilang yang lebih kompleks dibanding dengan topping refinery. Pada jenis konfigurasi ini, produk diesel dan fraksi ringan $\left(\mathrm{C}_{1}-\mathrm{C}_{4}\right)$ yang dihasilkan oleh atmospheric crude unit diproses lebih lanjut 
untuk mendapatkan produk final yang sesuai spesifikasi namun tidak menggunakan proses cracking [2].

Produk yang dihasilkan oleh hydroskimming dapat berupa produk fraksi ringan $\left(\mathrm{C}_{1}-\mathrm{C}_{4}\right)$, finished gasoline, finished jet fuel, dan ultralow sulfur diesel. Dan juga fraksi ringan $\left(\mathrm{C}_{1}-\mathrm{C}_{4}\right)$ dapat ditingkatkan kualitasnya misal menggunakan proses isomerisasi butana untuk meningkatkan harga jualnya. Konfigurasi jenis ini juga dapat meningkatkan fleksibilitas dalam penggunaan feed minyak mentah namun tetap dibatasi pada minyak mentah berjenis light crude, namun tidak harus berjenis light sweet crude. Terdapat unit hydrotreater dalam konfigurasi tipe hydroskimming refinery. Unit tersebut berfungsi untuk menghilangkan impurities seperti sulfur, nitrogen, dan oksigen sebagai bentuk kontrol dari kualitas produk ataupun sebagai preparasi awal feed untuk nantinya diolah lebih lanjut pada unit naptha reformer dan FCC. Selain untuk menghilangkan impuritis, unit hydrotreater juga berfungsi untuk menghilangkan deposisi logam yang muncul akibat adanya proses hidrogenisasi dan dekomposisi organometallic pada guard catalytic reactor yang menghasilkan deposisi logam pada pori-pori katalis. Selain itu unit hydrotreater juga berfungsi untuk menjenuhkan senyawa olefin dan menstabilkannya.

\section{Cracking}

Cracking refinery merupakan konfigurasi yang lebih kompleks dibanding dua tipe konfigurasi sebelumnya. Dibandingkan dengan hydroskimming, pada cracking refinery terdapat dua kemungkinan konfigurasi yakni yg pertama ditambahkan vacuum tower dan Fluid Catalytic Cracking (FCC) yang dilengkapi dengan unit alkylation atau ditambahkan hydrocracker untuk mengubah vacuum gas oil, pada beberapa kilang justru memiliki kedua konfigurasi tersebut untuk mendongkrak kualitas dari produk agar mencapai spesifikasi yang tinggi seperti misalnya US Tier III gasoline. Hasil dari vacuum tower yakni vacuum residue tetap dijual sebagai fuel oil (biasanya masih mengandung sulfur yang tinggi) atau diolah menjadi asphalt. Dan juga diperlukan produksi hidrogen untuk mensupport unit hydrocracker agar dapat memproduksi ultralow sulfur jet dan ultralow sulfur diesel. [2]

\section{Full Conversion/Complex}

Jenis konfigurasi kilang minyak yang terakhir adalah full conversion/complex refinery. Pada konfigurasi jenis ini terdapat proses "coking" atau "high-conversion" refinery. Fitur utama pada proses coking adalah konversi dari sisa-sis a vacuum residue menjadi produk bernilai jual tinggi. Pabrik seperti ini sangat dimungkinkan dapat mengintegrasikan antara produksi bahan kimia kedalam kilang minyak, sebagai contoh adalah produksi bahan bakar.

Terdapat dua kemungkinan konfigurasi dalam tipe full conversion. Sampai pada titik tertentu sekilas terlihat bahwa kilang jenis ini seperti kilang bertipe cracking refinery, namun hal utama yang membedakan kilang konfigurasi ini dengan kilang bertipe cracking adalah kilang bertipe konfigurasi ini terdapat tambahan proses coking, heavy oil cracking (seperti
FCC residue), deasphalting, dan/atau residue hydrocracking [2]. Berdasarkan hasil analisa tipe proses, maka dipilih tipe konfigurasi hydroskimming refinery. Untuk proses produksi skala kecil pada mini refinery, dinilai akan menguntungkan. Selain itu karena salah satu produk yang diinginkan berupa finished gasoline, maka konfigurasi yang paling sederhana dan paling memungkinkan adalah tipe konfigurasi hydroskimming refinery.

\section{B. Bahan Baku Yang Digunakan}

Bahan baku yang digunakan berasal dari sumur minyak Bekapai. dengan spesifikasi minyak mentah di Bekapai tersedia pada tabel berikut:

Tabel 1.

Spesifikasi Minyak Mentah Bekapai

\begin{tabular}{c|c}
\hline \hline Massa Jenis $\left(\mathrm{kg} / \mathrm{m}^{3}\right)$ & 781.1602 \\
API & 42,59 \\
Berat Molekuler & 151,7 \\
Kandungan Belerang $(\%$ & 0,045 \\
wt) & 10,388 \\
Pour Point $\left({ }^{\circ} \mathrm{C}\right)$ & 0,866 \\
Specific Gravity & 11,32 \\
Watson UOP K-factor
\end{tabular}

\section{Uraian-uraian Proses}

Berikut adalah uraian proses pada kilang minyak skala kecil:

\section{1) Preheating dan Separation}

Minyak mentah yang berasal dari Oseil dan Bula, ditampung di tangki penampung dengan kondisi operasi suhu $30^{\circ} \mathrm{C}$ dan tekanan 30 bar. Minyak mentah ini kemudian dipompa dengan menggunakan pompa sentrifugal menuju Heat exchanger I. Tujuan dari pemompaan ini adalah untuk memindahkan fluida (crude oil) dari tempat yang lebih rendah ke tempat yang lebih tinggi serta meningkatkan kecepatan alir dari fluida tersebut. Pompa yang digunakan adalah non positive displacement pump jenisnya pompa sentrifugal.

Minyak mentah dipompa menuju heat exchanger yang dipasang secara seri yakni HE-1, HE-2, HE-3. Crude oil masuk HE melalui bagian tube, sedangkan media pemanas masuk bagian shell dengan arah aliran counter current. Minyak mentah masuk $\mathrm{HE}-1$ pada suhu $30^{\circ} \mathrm{C}$ dan keluar pada suhu $60^{\circ} \mathrm{C}$ dengan media pemanas Kerosene yang merupakan outlet dari crude distillation unit. Lalu crude oil yang sudah dipanaskan dialirkan ke HE-2 untuk proses pemanasan selanjutnya dengan menggunakan media pemanas heavy gas oil yang merupakan side stream produk dari kolom ADU, sehingga crude oil outlet HE-2 ini memiliki suhu sekitar $90^{\circ} \mathrm{C}$. Kemudian proses pemanasan dilanjutkan dalam HE-3 dengan media pemanas berupa stabilized naphtha yang merupakan produk dari kolom naptha stabilizer, sehingga suhu crude oil menjadi $130^{\circ} \mathrm{C}$. Tujuan dari pemanasan ini adalah untuk meringankan beban furnace dengan memanfaatkan aliran panas yang dihasilkan oleh proses. Setelah keluar dari unit preheater kemudian feed akan memasuki proses separasi dengan pre-flash separation 
Setelah keluar dari unit preheater, crude oil dipanaskan menggunakan furnace hingga bersuhu $220^{\circ} \mathrm{C}$ dan teruapkan secara parsial. Crude oil yang keluar dari furnace berada pada keadaan dua fase yakni fase uap dan fase liquid. Pada kolom ini crude oil di flash menjadi dua aliran, yaitu aliran top dan bottom. Dimana aliran top berupa light product (fraksi ringan) sedangkan aliran bottom berupa bottom liquid. Tujuan dari pemisahan ini adalah untuk meringankan beban furnace yang ada pada crude distillation unit. [3]

Kemudian bottom liquid dari flash kolom dialirkan dengan pompa menuju furnace (Q-161). Pada furnace, crude oil mengalami pemanasan maksimal dengan suhu optimal hingga $220^{\circ} \mathrm{C}$. Hal ini bertujuan untuk mencapai suhu optimum kolom fraksinasi sehingga fase cair dan uap akan terpisah dengan baik. Pada dasarnya, semakin tinggi suhu furnace maka akan semakin tinggi pula total produk yang dihasilkan. Namun semakin tinggi suhu furnace maka semakin tinggi pula total biaya operasinya.

Selain itu, apabila suhu operasi terlalu tinggi (lebih dari $360^{\circ} \mathrm{C}$ ) akan menyebabkan cracking pada rantai hidrokarbon dan membentuk senyawa baru yang tidak dikehendaki, seperti olefin yang mempunyai sifat stabil terhadap oksidasi serta dapat mempercepat timbulnya kerak yang menempel pada dinding furnace. Terbentuknya kerak akan menghambat perpindahan panas sehingga efisiensi furnace akan turun.

Pengendalian temperatur pada furnace dapat dilakukan dengan mengendalikan aliran fuel oil. Jika temperatur terlalu tinggi maka aliran fuel oil diperkecil, sebaliknya jika kurang tinggi maka aliran fuel oil diperbesar.

\section{2) Crude Distillation Unit}

Crude oil yang keluar dari furnace dialirkan ke kolom distilasi. Kolom distilasi ini terdiri dari sebuah kolom fraksinasi utama dengan jumlah tray sebanyak 43 buah yang juga dilengkapi dengan tiga buah kolom stripper. Pada bagian bottom diinjeksikan steam yang bertujuan untuk menyediakan panas serta memperkecil tekanan parsial hidrokarbon. Hal ini dikarenakan, ketika tekanan parsial hidrokarbon turun, maka penguapan hidrokarbon menjadi lebih besar sehingga pemisahan fase uap dan liquida menjadi lebih sempurna. Steam yang dimasukkan adalah steam kering, digunakan untuk menghindari tekanan total yang besar pada kolom fraksinasi. Bila steam yang masuk mengandung air dan suhu kolom fraksinasi lebih tinggi dari suhu steam, maka air yang masuk akan menguap dalam kolom fraksinasi sehingga tekanan total pada kolom fraksinasi akan meningkat.

Pada kolom fraksinasi ini, crude oil akan terpisah menjadi residu atmosferik pada bottom, top produk berupa naphta, sedangkan sides stream yang ada adalah kerosene, LGO, dan HGO. Dalam kolom fraksinasi ini juga terdapat proses pumparound, yaitu proses mengambil sebagian liquid dari kolom dari keadaan saturated kemudian didinginkan menjadi subcooled dan dikembalikan lagi ke kolom. Tujuannya adalah untuk mengembunkan kembali fraksi yang tidak seharusnya menguap. Misalnya, pumparound dari LGO akan mengembunkan kembali residu yang ikut teruapkan bersama uap LGO. Pada top produk kolom stripper 1 berupa kerosene, top produk kolom stipper 2 berupa LGO, dan top product kolom stripper 3 berupa $\mathrm{HGO}$ yang direfluks atau dikembalikan lagi ke kolom fraksinasi.

Kinerja kolom fraksinasi dipengaruhi oleh suhu dan tekanan operasinya. Jika temperatur kolom fraksinasi terlalu tinggi, maka banyak fraksi berat yang terikut ke produk atas, akibatnya produk tersebut memiliki titik didih akhir lebih tinggi dari spesifikasi yang diharapkan. Sebaliknya, bila temperatur terlalu rendah, maka masih terdapat fraksi ringan yang belum teruapkan, akibatnya produk yang dihasilkan menjadi kurang optimal. Pengendalian kolom ini dilakukan dengan jalan menggunakan proses refluks, yaitu cairan hasil pengembunan uap dari produk puncak kolom yang dikembalikan ke dalam kolom pada tray teratas. Jika hendak menurunkan temperatur kolom, maka aliran refluks dinaikkan. Sebaliknya, jika temperatur kolom tinggi, maka aliran refluks diturunkan sehingga temperaturnya menjadi normal. Sedangkan tekanan kolom fraksinasi akan berpengaruh pada proses penguapan. Kenaikan tekanan akan menghambat penguapan fraksi minyak pada suhu operasi yang sama. Bila tekanan kolom fraksinasi naik, maka produk puncak kolom akan mempunyai titik didih akhir yang rendah, sedangkan penurunan tekanan dalam kolom akan berakibat naiknya titik didih akhir puncak kolom. Kenaikan tekanan pada kolom fraksinasi dapat diakibatkan oleh beberapa faktor diantaranya adalah kecepatan penguapan yang tinggi, kecepatan aliran umpan masuk yang besar, temperatur puncak kolom yang naik, kegagalan kondensasi uap dan banyaknya injeksi steam. Pada umumnya tekanan cukup stabil, sehingga pengaruh perubahannya terhadap temperatur relatif kecil. Pengaturan dan pengendalian permukaan cairan juga perlu dilakukan pada kolom fraksinasi. Apabila permukaan cairan terlalu rendah, maka waktu tinggal cairan akan berkurang akibat dari banyaknya fraksi yang terikut. Selain itu, berkurangnya residence time juga menyebabkan penurunan titik didih awal. Pada umumnya permukaan cairan pada dasar kolom fraksinasi dijaga sekitar 50-70\% tingginya. Pengaturan level cairan dilakukan dengan jalan mengatur laju aliran keluar dari dasar kolom. Apabila level terlalu tinggi, melebihi batas maksimum yang ditetapkan, maka control valve akan membuka lebih besar.

Kecepatan aliran umpan harus dipertahankan agar temperatur pemanasan umpan keluar heater stabil. Bila kecepatan alir umpan terlalu cepat, maka penguapan pada kolom fraksinasi akan terganggu karena semakin banyak fraksi berat yang teruapkan, sehingga kualitas produk tidak sesuai dengan yang diinginkan. Aliran refluks juga berpengaruh pada temperatur atas kolom fraksinasi. Jika kecepatan aliran refluks turun, maka temperatur atas kolom akan naik. Oleh sebab itu, ketepatan aliran refluks dilakukan dengan memasang pengontrol yang dihubungkan dengan kolom fraksinasi bagian atas.

\section{Stabilizer Column}

Debutanizer digunakan pada refinery untuk menghilangkan butana dan komponen ringan dari aliran produk feed. Pada 
kolom stabilizer akan terjadi pemisahan produk gas $\left(\mathrm{C}_{3} / \mathrm{C}_{4}\right)$ yang keluar dari atas kolom dan dari bawah kolom $\left(\mathrm{C}_{5}{ }^{+}\right)[2]$.

\section{E. Gasoline Blending}

Untuk meningkatkan fleksibilitas jenis produk dan profit, umumnya suatu kilang akan melakukan blending produk dari produk dasar yang telah diperoleh untuk menghasilkan suatu produk lain yang sesuai dengan spesifikasi yang diinginkan. Sebagai contoh untuk mendapatkan produk bensin berjenis premium yang memiliki angka oktan 88 maka perlu dilakukan blending terhadap produk straight run naptha yang dihasilkan oleh proses kilang dengan komponen utama bensin berangka oktan tinggi (HOMC - High Octane Mogas Component). Blending produk akan dilakukan secara batch menggunakan storage yang pengadukannya dibantu menggunakan pompa dengan cara mengalirkan straight run naphtha menuju storage sehingga nantinya akan tercipta pusaran didalam storage, yang kemudian nantinya komponen blending HOMC akan ditambahkan dengan rasio tertentu sehingga didapatkan produk dengan angka oktan dengan spesifikasi tertentu [4].

\section{NERACA MASSA}

Berdasarkan hasil perhitungan neraca massa, dengan feed crude oil dari Bekapai,, berikut merupakan hasil perhitungan dari material balance pabrik Kilang Minyak Skala Kecil dimana kapasitas feed sebesar 10.000 barrel/hari dan HOMC 1970 barrel/hari produk gasoline yang dihasilkan sebesar 5384 barrel/hari [5].

\section{ANALISA EKONOMI}

Dari hasil perhitungan pada neraca ekonomi didapatkan Total Cost Investment pabrik ini sebesar Rp 292.774.958.752,83 dengan bunga $10,25 \%$ per tahun. Selain itu, diperoleh IRR sebesar $43 \%$ dan BEP sebesar 54,18\% dimana pengembalian modalnya selama 4,235 tahun. Umur dari pabrik ini diperkirakan selama 10 tahun dengan masa periode pembangunannya selama 2 tahun di mana operasi pabrik ini 330 hari/tahun [6].

\section{KESIMPULAN}

Berdasarkan hasil analisa ekonomi didapatkan nilai IRR sebesar $43 \%$ yang lebih tinggi dari suku bunga bank yaitu $10,25 \%$ per tahun dan BEP sebesar 54,18\% dimana pengembalian modalnya selama 4,235 tahun maka pabrik Produksi Gasoline pada Kilang Minyak Skala Kecil ini layak didirikan.

\section{DAFTAR PUSTAKA}

[1] K. ESDM, "Kajian Supply Demand Energi,” Jakarta, 2013.

[2] D. S. J. Jones, "Handbook of Petroleum Processing," Springer, 2006.

[3] L. G. Kaes, Refinery Process Modelling. USA: Kaes Enterprises, Inc, 2000.

[4] K. Marton, "Hydrocarbon Processing, Refinery Products,Product Blending," 2013.

[5] D. M. dan J. B. R. Himmelblau, Basic Principles and Calculations in Chemical Engineering 7th Edition. New Jersey, 2004.

[6] K. D. Peters, Max S. and Timmerhauss, Plant Design and Economics For Chemical Engineerings. Singapore: Mc Graw Hill, 1991. 